\title{
CONSTRUCTION RELATED DEATHS IN THE STATE OF NORTH CAROLINA IN THE RECENT DECADE BASED ON CAUSES RACES \& CITIES
}

\author{
Manish Venugopal \\ University of North Carolina, United States
}

\begin{abstract}
The purpose of this study is to evaluate the construction related deaths in the state of North Carolina in the recent decade. Data was obtained from North Carolina Department of Labor for a 10 year period from 2010-2019. An analysis was carried to determine the primary causes, races, and cities of construction related mortality. The study evaluated 154 deaths based on leading causes, cities, and races. Results indicated fall from height being the primary cause of death in $43.51 \%$ of deaths. Raleigh alone accounted for $1 / 3^{\text {rd }}$ of the deaths. In addition, white Americans accounted for almost $46.75 \%$ of the people dead from the assessed incidents.
\end{abstract}

Keywords: Construction safety; Fall from heights; Cities; Races; Fatality causes.

Cite this Article: Manish Venugopal, Construction Related Deaths in the State of North Carolina in the Recent Decade Based on Causes, Races \& Cities. International Journal of Civil Engineering and Technology, 11(3), 2020, pp. 35-40.

https://iaeme.com/Home/issue/IJCIET?Volume=11\&Issue=3

\section{INTRODUCTION}

(Max Roser, 2020) stated that global population as of 2019 had increased from 1 billion in 1800 to 7.7 billion. (Bureau, 2020) stated, that United States alone consists of 328.5 Million people. Due to this rapid growth, humans are transforming the predominant naturals landscapes into infrastructures (Foley et al., 2005; Venugopal, 2019). Rapid growth \& development across has made construction industry as one of the largest across the world (Venugopal, 2020). As of 2018, the construction industry consisted of 9.04 Million people in its workforce according to the bureau of labor statistics (Bureau of Labor Statistics, 2018).

Although construction industry employs around 6\% of the people in the United States, it is considered to be one of the most dangerous industries to be employed. In 2002, the industry accounted for $20.03 \%$ of occupational related deaths in the country (Brunette, 2004). In excess of 1000 fatal injuries have been documented in the United States between 1995 to 2008 from the construction industry in the United States (Albert \& Hallowell, 2012).

The industry consisted of approximately $70 \%$ of workers on field who are susceptible to the hazards of the industry on day to day basis (Bureau of Labor Statistics, 2018). It involves general construction laborers, carpenters, electricians, supervisors, plumbers, roofers, painters, 
equipment operators, mechanical installers, etc. These people have to perform tasks involving varying degrees of risks due to the handling of heavy \& complex tools, equipment, \& machinery. In the past decades, the major causes of deaths have been from fall from heights (Janicak, 1998), electrocution (McCann, Hunting, Murawski, Chowdhury, \& Welch, 2003), struck between objects (Rundmo, 1992), \& crushed by objects (heavy equipment \& truck related deaths) (McCann, 2006). In addition to the causes, the industry consists of mostly $90 \%$ of male workers compared to $10 \%$ female workers. In the construction laborers category alone, there are approximately $71 \%$ white (Bureau of Labor Statistics, 2018). The industry also accounts for approximately 2.8 million Hispanic workers (Training, 2015). The state of North Carolina has seen a construction boom in the recent decade. It is in the top 10 states accounting for construction related employments (Bureau of Labor Statistics, 2017). With the construction industry going strong in the region, the risk also increases. Therefore, the objective of this study is to investigate the primary causes of construction related deaths in the state of North Carolina. In addition, determine the major races and cities which accounts for these deaths. The scope of this objective is to identify the preliminary causes and provide a solution to reduce the deaths based on the previous literature available.

\section{METHODS \& ANALYSIS:}

Data was obtained from North Carolina Department of Labor for the past 10 years from 2010 to 2019. It consisted of deaths based on various industries, causes, races, cities, counties from 2010 to 2019 . For the purpose of the study, the data regarding construction industry alone was evaluated. It consisted of total number of deaths per year with the causes of the death, location where the incident took place and the person involved in the incident.

Summation of number of deaths across each individual year was given from which the total sum of deaths for the 10 year period was determined. From this, the average number of deaths across 10 year period was calculated.

Table 1 Number of deaths across the 10 year period from 2010-2019

\begin{tabular}{|c|c|}
\hline Year & Number of Death/Year \\
\hline 2010 & 18 \\
\hline 2011 & 17 \\
\hline 2012 & 10 \\
\hline 2013 & 7 \\
\hline 2014 & 17 \\
\hline 2015 & 15 \\
\hline 2016 & 16 \\
\hline 2017 & 12 \\
\hline 2018 & 24 \\
\hline 2019 & 18 \\
\hline Sum & 154 \\
\hline Average & 15.4 \\
\hline
\end{tabular}

Similarly, the summation and average number of deaths based on each causes, races and cities were determined across individual years and the 10 year period from 2010 to 2019. 
Manish Venugopal

Table 2 Causes of deaths across the years

\begin{tabular}{|c|c|c|c|c|c|c|c|}
\hline \multirow{2}{*}{ Year } & \multicolumn{7}{|c|}{ Causes } \\
\cline { 2 - 8 } & Fall & Electrocution & $\begin{array}{c}\text { Struck by } \\
\text { object }\end{array}$ & $\begin{array}{c}\text { Crushed by } \\
\text { object }\end{array}$ & Explosion & Other & Sum \\
\hline 2010 & 10 & 3 & 4 & 0 & 0 & 1 & 18 \\
\hline 2011 & 7 & 1 & 4 & 0 & 0 & 5 & 17 \\
\hline 2012 & 5 & 1 & 3 & 0 & 0 & 1 & 10 \\
\hline 2013 & 3 & 0 & 3 & 0 & 0 & 1 & 7 \\
\hline 2014 & 4 & 1 & 10 & 1 & 0 & 1 & 17 \\
\hline 2015 & 7 & 4 & 3 & 1 & 0 & 0 & 15 \\
\hline 2016 & 7 & 1 & 4 & 1 & 0 & 3 & 16 \\
\hline 2017 & 5 & 1 & 4 & 2 & 0 & 0 & 12 \\
\hline 2018 & 12 & 1 & 7 & 1 & 0 & 3 & 24 \\
\hline 2019 & 7 & 1 & 5 & 1 & 0 & 4 & 18 \\
\hline Sum & 67 & 14 & 47 & 7 & 0 & 19 & 154 \\
\hline Average & 6.7 & 1.4 & 4.7 & 0.7 & 0 & 1.9 & 15.4 \\
\hline
\end{tabular}

CAUSES OF FATALITIES

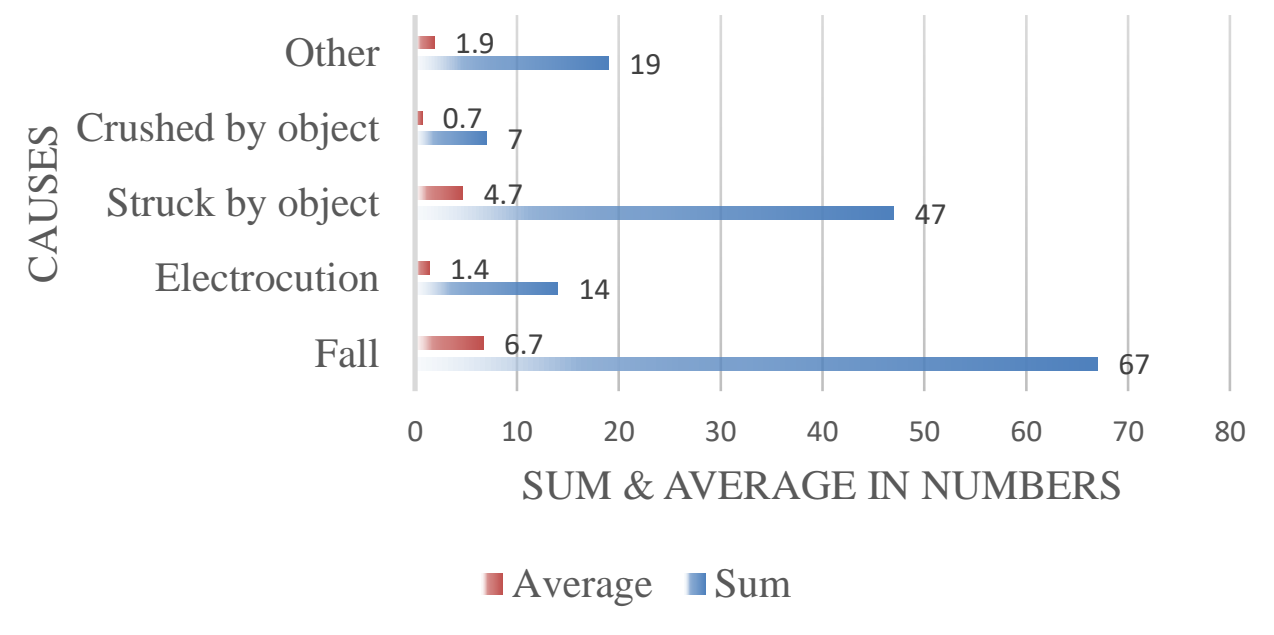

Figure 1 Causes of Deaths across the years

Table 3 Races affected by deaths across the years

\begin{tabular}{|c|c|c|c|c|c|c|c|}
\hline \multirow{2}{*}{ Year } & \multicolumn{7}{|c|}{ Race } \\
\cline { 2 - 8 } & Black & Hispanic & White & $\begin{array}{c}\text { Native } \\
\text { American }\end{array}$ & Asian & Other & Sum \\
\hline 2010 & 1 & 6 & 11 & 0 & 0 & 0 & 18 \\
\hline 2011 & 4 & 8 & 4 & 0 & 1 & 0 & 17 \\
\hline 2012 & 1 & 4 & 5 & 0 & 0 & 0 & 10 \\
\hline 2013 & 0 & 3 & 4 & 0 & 0 & 0 & 7 \\
\hline 2014 & 0 & 9 & 8 & 0 & 0 & 0 & 17 \\
\hline 2015 & 2 & 6 & 7 & 0 & 0 & 0 & 15 \\
\hline 2016 & 2 & 4 & 10 & 0 & 0 & 0 & 16 \\
\hline 2017 & 1 & 5 & 4 & 1 & 1 & 0 & 12 \\
\hline 2018 & 2 & 10 & 10 & 0 & 0 & 2 & 24 \\
\hline 2019 & 1 & 8 & 9 & 0 & 0 & 0 & 18 \\
\hline Sum & 14 & 63 & 72 & 1 & 2 & 2 & 154 \\
\hline Average & 1.4 & 6.3 & 7.2 & 0.1 & 0.2 & 0.2 & 15.4 \\
\hline Percentage & $9.09 \%$ & $40.91 \%$ & $46.75 \%$ & $0.65 \%$ & $1.30 \%$ & $1.30 \%$ & \\
\hline
\end{tabular}


Construction Related Deaths in the State of North Carolina in the Recent Decade Based on Causes, Races \& Cities

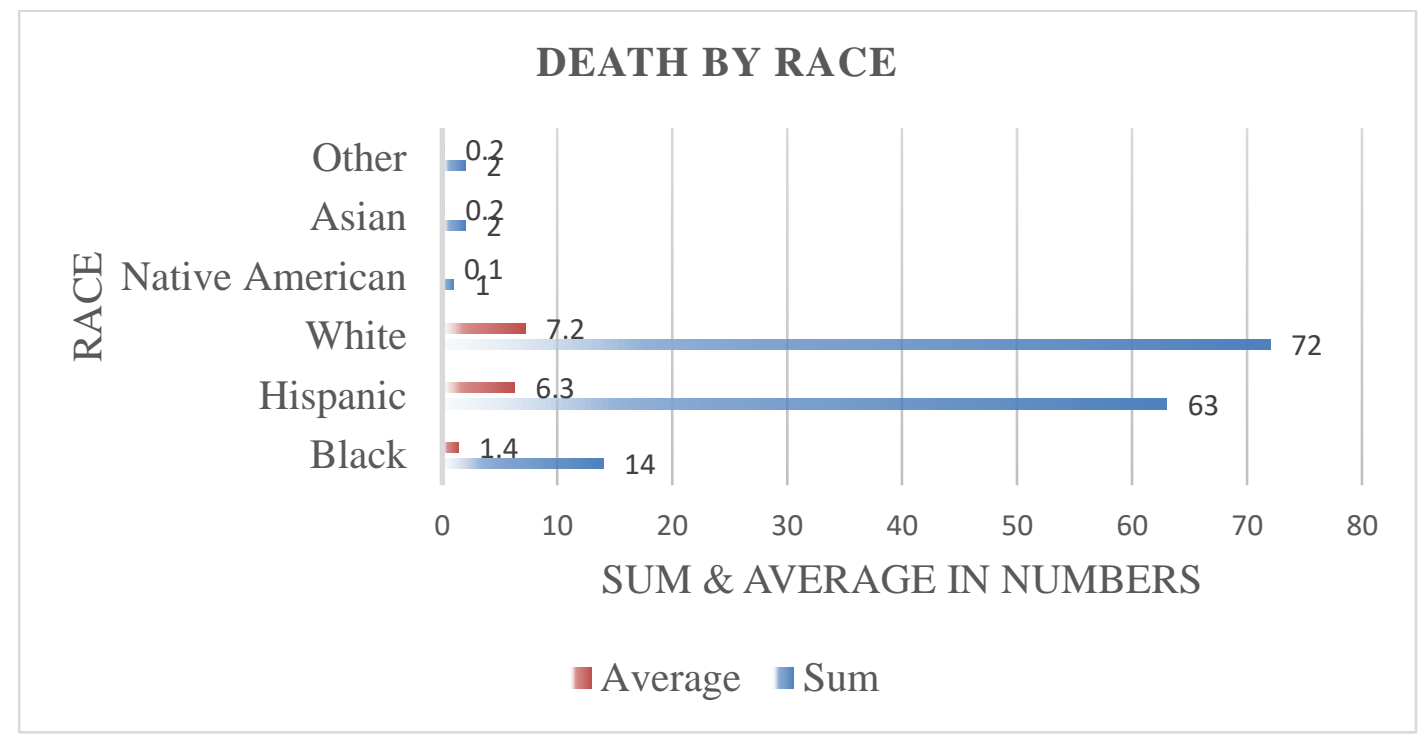

Figure 2 Races affected by deaths across the years

Table 4 Cities affected by deaths across the years

\begin{tabular}{|c|c|c|c|c|c|c|c|}
\hline \multirow{2}{*}{ Year } & \multicolumn{7}{|c|}{ City } \\
\cline { 2 - 8 } & Asheville & Charlotte & Raleigh & Wilmington & $\begin{array}{c}\text { Winston- } \\
\text { Salem }\end{array}$ & Other & Sum \\
\hline 2010 & 1 & 5 & 7 & 3 & 2 & 0 & 18 \\
\hline 2011 & 1 & 4 & 11 & 0 & 1 & 0 & 17 \\
\hline 2012 & 1 & 4 & 4 & 0 & 1 & 0 & 10 \\
\hline 2013 & 1 & 0 & 1 & 2 & 2 & 1 & 7 \\
\hline 2014 & 3 & 6 & 3 & 2 & 2 & 1 & 17 \\
\hline 2015 & 1 & 2 & 7 & 4 & 1 & 0 & 15 \\
\hline 2016 & 1 & 6 & 2 & 4 & 3 & 0 & 16 \\
\hline 2017 & 1 & 4 & 2 & 1 & 3 & 1 & 12 \\
\hline 2018 & 3 & 3 & 9 & 4 & 5 & 0 & 24 \\
\hline 2019 & 1 & 3 & 7 & 2 & 5 & 0 & 18 \\
\hline Sum & 14 & 37 & 53 & 22 & 25 & 3 & 154 \\
\hline Average & 1.4 & 3.7 & 5.3 & 2.2 & 2.5 & 0.3 & 15.4 \\
\hline Percentage & $9.09 \%$ & $24.03 \%$ & $34.42 \%$ & $14.29 \%$ & $16.23 \%$ & $1.95 \%$ & \\
\hline
\end{tabular}

DEATH B Y CITY

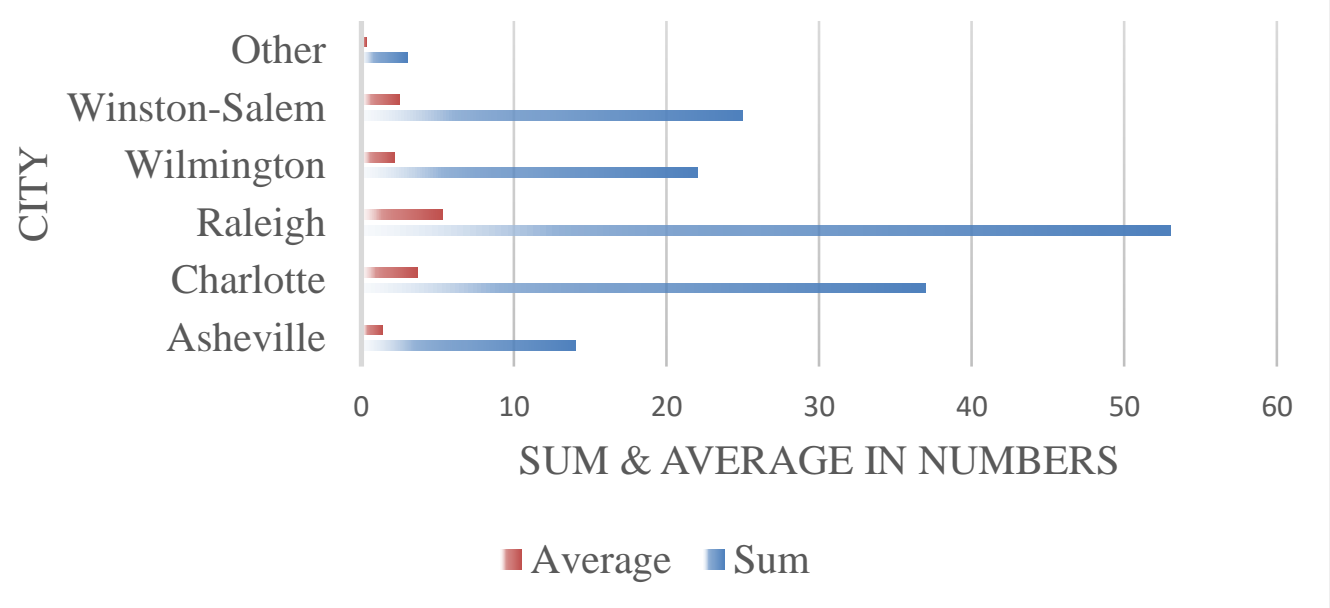

Figure 3 Cities affected by deaths across the years 


\section{RESULTS \& DISCUSSION}

- From figure 1, it was evident that the major source of construction related deaths were caused by fall from heights accounting for $67(43.51 \%)$ of the 154 deaths. This was followed by struck by object 47 (30.52\%) of the 154 deaths. Crushed by object was the least with 7 deaths accounting for $4.55 \%$.

- Figure 2 indicated that the white Americans and the Hispanic workers were the most affected accounting for $72(46.75 \%)$ and $63(40.91 \%)$ deaths out of the 154 respectively. Native Americans were the least affected with 1 person dead accounting for $0.65 \%$.

- Similarly, from Figure 3 it was clear that Raleigh and Charlotte accounted for the highest number of deaths with $53(34.42 \%)$ and $37(24.03 \%)$ out of the 154 respectively.

(Chi, Chang, \& Ting, 2005) stated fall from heights (falling through open floors, ladders, roof edges, scaffolds, lifts) \& (McCann, 2006) struck by object (heavy equipment, machineries, trucks) are two of the major causes related construction related deaths. Similarly, these two causes accounted for 114 of the 154 deaths in the past decade in the state of North Carolina. This alone accounts of approximately $74 \%$ of the deaths occurred in the region.

In terms of races, white workers have been the most affected, they accounted for $46.75 \%$ of the deaths. But they account for $71 \%$ construction laborers. (Dong, Fujimoto, Ringen, \& Men, 2009) stated, Hispanic workers accounting 2/3 of the fall related deaths in the past decade. Now they account for $40.91 \%$ of deaths is raising concerns compared to their white, native American, \& black counterparts. (Training, 2015) stated that, 73\% of the Hispanic workers were immigrants born outside the United States. There should be more training \& prevention measures provided to them to reduce the risk.

\section{CONCLUSION}

Construction related deaths \& solutions have been researched for decades in the United States. There have been various reforms by mandating the usage of fall protections devices, personal protective equipment, safety meetings \& related training. However, the results indicated the causes of deaths such as fall from heights, struck by objects, electrocution, \& crushed by objects haven't changed in the past decade in the state of North Carolina.

As stated above, the fall from heights \& struck by objects alone have accounted for $74 \%$ of the deaths. Similarly, white and Hispanic workers were the most affected by race. Although Hispanic workers contribute around $28.6 \%$ of the work-force they account for more than $2 / 5$ of the fatality. There should be mandatory ground level education related to construction safety for them.

Although we take preventive measures related to construction safety human factors tends to be the major cause of deaths (Perlman, Sacks, \& Barak, 2014). Moving forward, there should be research related to hazard recognition rather than hazard prevention (Albert \& Hallowell, 2012). Workers should be taught to recognize the potential hazards instead of preventing them. 
Construction Related Deaths in the State of North Carolina in the Recent Decade Based on Causes, Races \& Cities

\section{REFERENCES}

[1] Albert, A., \& Hallowell, M. R. (2012). Hazard recognition methods in the construction industry. Paper presented at the Construction Research Congress 2012: Construction Challenges in a Flat World.

[2] Brunette, M. J. (2004). Construction safety research in the United States: targeting the Hispanic workforce. Injury Prevention, 10(4), 244-248.

[3] Bureau of Labor Statistics, U. (2017). Construction Data. Retrieved from https://www.conexpoconagg.com/news/10-best-states-for-construction-jobs/

[4] Bureau of Labor Statistics, U. (2018). Construction Data. Retrieved from https://datausa.io/profile/naics/construction-group

[5] Bureau, U. C. (2020). Census Data. Retrieved from https://www.census.gov/quickfacts/fact/table/US/PST045219

[6] Chi, C.-F., Chang, T.-C., \& Ting, H.-I. (2005). Accident patterns and prevention measures for fatal occupational falls in the construction industry. Applied ergonomics, 36(4), 391400 .

[7] Dong, X. S., Fujimoto, A., Ringen, K., \& Men, Y. (2009). Fatal falls among Hispanic construction workers. Accident Analysis \& Prevention, 41(5), 1047-1052.

[8] Foley, J. A., DeFries, R., Asner, G. P., Barford, C., Bonan, G., Carpenter, S. R.,. Gibbs, H. K. (2005). Global consequences of land use. science, 309(5734), 570-574.

[9] Janicak, C. A. (1998). Fall-related deaths in the construction industry. Journal of Safety Research, 29(1), 35-42.

[10] Max Roser, H. R. a. E. O. O. (2020). World Population Growth. Retrieved from https://ourworldindata.org/world-population-growth

[11] McCann, M. (2006). Heavy equipment and truck-related deaths on excavation work sites. Journal of Safety Research, 37(5), 511-517.

[12] McCann, M., Hunting, K. L., Murawski, J., Chowdhury, R., \& Welch, L. (2003). Causes of electrical deaths and injuries among construction workers. American journal of industrial medicine, 43(4), 398-406.

[13] Perlman, A., Sacks, R., \& Barak, R. (2014). Hazard recognition and risk perception in construction. Safety Science, 64, 22-31.

[14] Rundmo, T. (1992). Risk perception and safety on offshore petroleum platforms-Part II: Perceived risk, job stress and accidents. Safety Science, 15(1), 53-68.

[15] Training, T. C. f. C. R. a. (2015). CPWR. Retrieved from https://www.cpwr.com/chartbook-6th-edition-labor-force-characteristics-hispanic-workers-construction-and-other

[16] Venugopal, M. (2019). Evaluating Pollutant Concentrations in Urban Streams Based on Precipitation, Network of Stormwater BMPs, and Impervious Cover. The University of North Carolina at Charlotte.

[17] Venugopal, M. (2020). Necessities, Properties, \& Merits of Using Geopolymer Concrete. International Journal of Engineering and Advanced Technology, 9, 3592-3594. doi:10.35940/ijeat.C6076.029320 